\title{
Fetal Movement Counting and Maternal Depression: A Randomized, Controlled Trial
}

\author{
Masoumeh Delaram, ${ }^{1, *}$ Loabat Jafar-Zadeh, ${ }^{2}$ and Sahand Shams ${ }^{3}$ \\ ${ }^{1}$ Midwifery Group, School of Nursing and Midwifery, Shahrekord University of Medical Sciences, Shahrekord, IR Iran \\ ${ }^{2}$ Obstetrics and Gynecology group, School of Medicine, Shahrekord University of Medical Sciences, Shahrekord, IR Iran \\ ${ }^{3}$ Veterinary Group, School of Veterinary Medicine, Shahrekord University, Shahrekord, IR Iran \\ "Corresponding author: Masoumeh Delaram, Midwifery Group, School of Nursing and Midwifery, Shahrekord University of Medical Sciences, Shahrekord, IR Iran. Tel: \\ +98-3813335648, Fax: +98-3813346714, E-mail: masoumehdelaram@yahoo.com
}

Received 2016 February 11; Revised 2016 August 12; Accepted 2017 February 08.

\begin{abstract}
Background: The women in pregnancy and postpartum are susceptible to psychological problems such as anxiety and depression. Many studies conducted on postpartum depression, but few studies have examined the depression in pregnancy and have focused on ways to treat it.

Objectives: The purpose of present study was to detect the fetal movement counting on depression of mother in the third trimester of pregnancy.

Methods: In a Randomized controlled trial, 66 women with a singleton pregnancy and mild and moderate depression based on Beck Inventory Scale, were randomly allocated either to perform daily fetal movement counting from 28 week to 37 ( $n=32)$ or control group $(\mathrm{n}=34)$. Analysis was performed with SPSS 16 and a $\mathrm{P}<0.05$ was considered significant.

Results: In the intervention group, the mean of depression scores was $14.56 \pm 4.66$ at 28 weeks and $13.65 \pm 4.00$ at 37 weeks and the difference was significant. The mean difference was 0.90 (95\% CI: $0.52-1.28, \mathrm{P}<0.001$ ). Also a significant difference was found in the control group between the 28 and 37 weeks of gestation with a mean difference of 0.32 (95\% CI: 0.01 - 0.62, P $<0.001$ ). There was not a significant difference in the mean of depression scores between the intervention and control group at 28 weeks. Also the difference was not significant at 37 weeks of gestation.

Conclusions: The level of depression was decreased at 37 weeks of gestation in the fetal movement counting and control group and the difference was not significant. The mother concern for reducing of fetal movements was similar in both groups.
\end{abstract}

Keywords: Beck Depression Inventory Scale, Fetal Movement Counting, Maternal Depression

\section{Background}

The women in the childbearing age are at high risk for depression [1] and the risk for depression can increase in pregnancy. In this time, depression can have devastating consequences for women and family [2]. Psychological disorders during the prenatal period greatly affect mothers and children [3] and may be correlated with poor prenatal outcomes such as preterm birth and low birth weight [4], low parent-child interactions, [5] and reduction in social and cognitive skills in children [6]. In different studies the estimated rates of prenatal severe depression were reported 8.5 and $11.0 \%$, and in postpartum, the rates were between 6.5 and $12.9 \%$ [7]. Individual factors, such as low income and unemployment are correlated with antenatal depression and unfortunately it can be affected by partner support and levels of social [8]. During pregnancy, psychiatric disorders including anxiety and depression increases the risk of postpartum depression and can lead to smoking, inattention, and poor nutrition. For the decreasing of depression in pregnancy, social sup- port, psychotherapy, and drug therapy are used. The studies recommend that the psychological interventions can help women and their children and treat the prenatal depression [9]. A study reported that the counting the fetal movements reduced the anxiety of mother [10]. Generally, maternal understanding of fetal movements is used to assess the fetal well-being [9] and nearly all pregnant women use this unstructured screening. The majority of women who have delivered a live-born baby reported that they are agree with the description that the daily feeling of fetal activity was important for them [11]. The counting of fetal movements is an indirect method for assessing the proper functioning of the nervous system, however, decreases in fetal activity requires other tests before considering interruption such as non-stress test (NST) [12]. The effects of fetal movement counting more have been studied on fetal well-being and also a few studies have been done on maternal concerns [13], anxiety [10], and maternal fetal attachment $[14,15]$ In this regard, a study has reported that the mothers who counted daily fetal movements in the third trimester, have reported less anxiety than the con- 
trol group [10]. Other studies have reported that the counting of fetal movements has increased the maternal fetal attachment [15] however this finding has not been confirmed in another study [14]. The women in pregnancy and postpartum are susceptible to psychological problems such as anxiety and depression and these can reduce the visits of prenatal care and may be associated with preterm birth and low birth weight [16]. Draper et al reported that with the counting of fetal movements, the majority of women were reassured about their child's health [17]. Therefore, it is necessary to do more researches to determine the level of concern associated with fetal movement counting. Despite many studies on postpartum depression, few studies have examined the depression in pregnancy and have focused on ways to treat it [18]. Due to the limited number of studies about the effect of fetal movement counting on maternal depression, the purpose of this study was to detect the effect of fetal movement counting on maternal depression.

\section{Methods}

In a Randomized, controlled trial, a total of 250 pregnant women signed the informed consent form and received the Beck inventory scale at 26 weeks of gestation for assessing the depression. One hundred seventy six women were excluded the study due to the lack of depression and 66 women with mild and moderate depression were included the study. Intervention group $(\mathrm{n}=$ 32 ) and control group $(\mathrm{n}=34)$ (Figure 1). The women in the intervention group were trained to do fetal movement counting and started to count the fetal movements from 28 to 37 weeks of gestation and in the control group, the participants received usal antenatal care without the counting of fetal movements. In Iran, almost all pregnant women get the antenatal care from health centers and in this study; eligible women were the women with singleton pregnancy. Pregnant women were recruited from October 2012 through December 2013 at two health centers. None of the women had participated previously in research on the reduction of fetal movements. Based on a pilot study, we calculated that 66 women were required to detect a 0.44 difference in depression scores between the two groups, with 80 percent power. After allocation, we were not able to blind the study for the participants or health care providers. At the first of study, there was no significant difference between the two groups in terms of demographic and clinical characteristics. An information brochure was given to women who were in the intervention group, where was taught how to chart the movements of the fetus and they were asked to count the fetal movements daily at the morning in left lateral position for one hour and chart from 28 weeks of gestation to 37 . To ensure the proper performance of fetal movement counting by mother, one person of the research team contacted by phone with mothers who were in the intervention group every two weeks. Also we asked them to show the chart to midwife in each visit of antenatal care.

The main outcome of the study was maternal depression, detected by the Beck depression inventory tool which was completed in 37 weeks of gestation. This tool was developed to assess the degree of depression [19] and validity and reliability of this has been confirmed in one study [20]. The ratings of the instruments are as follows: natural (0 - 9), mild depression (10 - 18), moderate depression (19 29 ), and severe depression $(\geq 30)$ [21]. Secondary outcome measures were the frequency of maternal reports of concerns about the decreased fetal movements and hospitalization due to it. All of participants in intervention group returned the chart of fetal movements. Among them, 92\% had completed the chart at least 4 times per week. Data analysis was performed using chi-square test and Fisher's exact test for categorial variables. We used the Independent $t$ test to compare the mean depression scores between the two groups and paired $t$ test for comparing the mean depression scores in 28 and 37 weeks of gestation in each group. Chi Square test and Fisher's exact test were used to test the statistical significance of differences in categorical of data. The significance level was set at $P=0.05$. The analyzer was blind for group assignment. Regional comittee for medical research ethics approved the study and the project was registered in www.clinicaltrials.gov. Protocol registration system IRCT201207103078N9.

\section{Results}

As showing in Table 1, no difference was found in age, job, body mass index (BMI), and level of education, between the two groups (Table 1).

The comparison of mean depression scores at weeks 28 and 37 in both groups is presented in Table 2 and indicated that there is a significant difference between 28 and 37 weeks in the intervention group, a mean difference was 0.90 (95\% CI: $0.52-1.28, \mathrm{P}<0.001$ ) and the fetal movement counting reduced the maternal depression. Also the difference was significant in the control group between 28 and 37 weeks of gestation with a mean difference of 0.32 (95\% CI: 0.01- 0.62, P < 0.001) and the maternal depression was reduced. Table 2 also indicates the comparing of mean scores of depression between the two groups at 28th and also 37 th with no significant difference (Table 2).

All of the women in the intervention group responded favorably to the use of counting charts. Forty-Four women 
26 Weeks of gestation

28-37 Weeks of gestation
250 Women signed the informed consent form and received the Beck Inventory Scale

Did not return the completed Beck Inventory Scale $(\mathrm{n}=8)$<smiles>[CH]1C2=C[Al]1C=C2</smiles>

242 Women completed the Beck Inventory Scale and 176 women were excluded due to the lack of depression

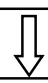

66 Women with mild and moderate depression were divided into the two groups

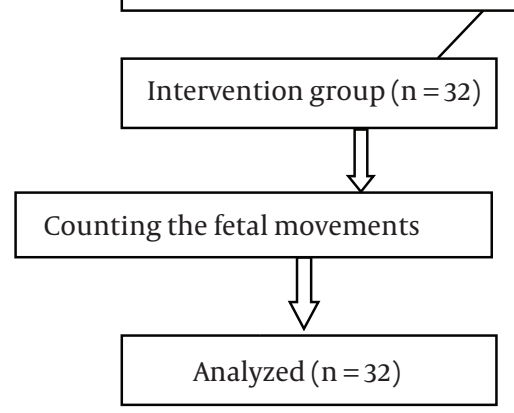

Without counting the fetal movements

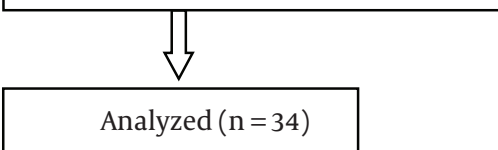

Figure 1. Flowchart of Participants in the Study

Table 1. Individual Characteristics of Women ${ }^{\mathrm{a}}$

\begin{tabular}{|c|c|c|c|}
\hline $\begin{array}{l}\text { Personal } \\
\text { Characteristics }\end{array}$ & $\begin{array}{c}\text { Control Group (n } \\
\quad=\mathbf{3 4})\end{array}$ & $\begin{array}{l}\text { Fetal Movement } \\
\text { counting Group } \\
\qquad(\mathrm{n}=32)\end{array}$ & PValue $^{\mathrm{b}}$ \\
\hline Age, $y$ & $27.00 \pm 3.63$ & $27.56 \pm 4.37$ & 0.58 \\
\hline BMI, $\mathrm{kg} / \mathrm{m}^{2}$ & $24.77 \pm 2.85$ & $24.36 \pm 2.50$ & 0.14 \\
\hline Job & & & 0.56 \\
\hline Employed & $14(13.1)$ & $16(16)$ & \\
\hline $\begin{array}{l}\text { Un- } \\
\text { Employed }\end{array}$ & $93(86.9)$ & $84(84)$ & \\
\hline Education & & & 0.06 \\
\hline $\begin{array}{l}\text { High } \\
\text { school } \\
\text { graduate }\end{array}$ & $25(23.4)$ & $28(28)$ & \\
\hline $\begin{array}{l}>\text { Collage } \\
\text { graduate }\end{array}$ & $82(76.6)$ & $72(72)$ & \\
\hline
\end{tabular}

Abbreviations: BMI, body mass index.

${ }^{\mathrm{a}}$ Values are expressed as mean \pm SD or No. (\%).

${ }^{\mathrm{b}}$ The $\mathrm{p}$ values refer to comparisons between the control and the intervention groups: Chi-Square test for categorical variables and t test for continuous variables. in the intervention group and 40 women in the control group were concerned once or more about the decreased of fetal movements during pregnancy and the difference was not significant. Comparing the mean of gestational age at the time of reduced fetal movements, number of concerns for decreased fetal activity, and number of mother hospitalization due to the decreased fetal movements is showing in Table 3 and indicating the no significant difference between the two groups (Table 3 ).

\section{Discussion}

The findings of study showed that the mothers who counted the fetal movements, reported less depression at 37 weeks of gestation and after the counting of fetal movements compared to 28 weeks. Also the findings indicated that the level of depression is reduced at 37 weeks compared to 28 weeks in the control group. However the reduction of depression was greater in the fetal movement counting group, but the difference was not significant. So far, there has not been a study that has examined the effects of fetal movement counting on maternal depression during pregnancy. In this regard, one study has been con- 
Table 2. Comparison of Mean Scores on Beck Scale for Depression Before the Intervention (28 weeks) and After the Intervention (37 weeks)

\begin{tabular}{|c|c|c|c|c|}
\hline Mean and SD of Scores & Control Group & Intervention Group & Mean Difference & P Value \\
\hline 28 weeks of gestation & $15.17 \pm 4.65$ & $14.56 \pm 4.66$ & 0.90 & 0.59 \\
\hline 37 weeks of gestation & $14.85 \pm 4.15$ & $13.65 \pm 4.00$ & 0.32 & 0.23 \\
\hline PValue & 0.039 & $<0.001$ & & \\
\hline
\end{tabular}

Table 3. Comparison of Gestational Age, Number of Concerns and Hospitalization Between the Two Groups ${ }^{\mathrm{a}}$

\begin{tabular}{lccc}
\hline Group & $\begin{array}{c}\text { Fetal Movement } \\
\text { Counting Group }\end{array}$ & Control Group & P Value \\
\hline $\begin{array}{l}\text { Gestational age at } \\
\text { the time of } \\
\text { reduced fetal } \\
\text { movements }\end{array}$ & $36.00 \pm 1.09$ & $35.57 \pm 2.08$ & 0.64 \\
$\begin{array}{l}\text { Number of } \\
\text { concerns for } \\
\text { decreased fetal } \\
\text { activity }\end{array}$ & $1.40 \pm 0.54$ & $1.61 \pm 1.19$ & 0.70 \\
$\begin{array}{l}\text { Number of } \\
\text { hospitalization for } \\
\text { decreased fetal } \\
\text { movements }\end{array}$ & $2.00 \pm 0.00$ & $1.96 \pm 0.18$ & 0.60 \\
\hline a Values are expressed as mean \pm SD. & & \\
\hline
\end{tabular}

ducted to reduce the risk of postpartum depression [22]. All women who have an anxiety or major depressive disorder during pregnancy or after childbirth, respond well to medication and in the majority of them complete remission of major depressive disorder is occurred. However, the symptoms of anxiety disorder are resistant and quality of life is compromised. Since the anxiety and depression are two debilitating disease during pregnancy, focusing on adjunctive therapies can be considered [23].

A study has reported that the interpersonal therapy can be effective in reducing depression during pregnancy [24]. In this context, a randomized controlled study of cognitive behavioral therapy was done in anxious and depressed women [25]. The evidence show that the home visits are very useful in this regard [26]. In the pregnant women awaiting amniocentesis, listening to music can reduce the level of plasma cortisol and reduce the maternal concern [27]. A study has reported that mother relaxation, improves the fetal neuro-behavioral indices A study has reported that mother relaxation, improves indices of fetal neuro-behavioral such as changes in fetal heart rate [28]. In a study which examined the active and passive relaxation on anxiety and maternal heart rate, both active and passive relaxation significantly reduced the state anxiety and maternal heart rate, but the effect was significantly greater with the active relaxation. In contrast, the passive relax- ation significantly reduced no adrenaline levels, whereas active did not. Both methods significantly reduced cortisol [29]. In general, to reduce the biological effects of depression during pregnancy, various methods may be needed from those which are most effective for decreasing the subjective psychological symptoms. It is still true that most of pregnant women do not report the depression, anxiety, and emotional and physical abuse that they have experienced and as a result, the health care providers are not informed and can not help them [30].

The symptoms of depression during pregnancy are lesser common than as postnatally [31] and midwives and obstetricians need to be trained to detect all this and offer appropriate support or help. If women are depressed, they should be referred to their general practitioner on antenatal and postnatal mental health. Talking therapy such as cognitive-behavioral therapy will be most appropriate for most depressed women [32]. The studies show that the mental state of the mother during pregnancy and postnatal period, can have long-term effects on her child, especially on neurodevelopmental outcomes. Research is still needed to determine which interventions during pregnancy are most effective for preventing of depression and improving child outcome [33]. The findings of one study showed when the mothers receive feedback about the health of the fetus, their stress and anxiety were significantly reduced [34]. A study reported that it is necessary to ensure the mothers regularly about the health of their fetus [35].

In current study, there was not a significant difference in the number of maternal concern for reducing of fetal movements between the two groups. Therefore, this criticism is not supported that the counting of fetal movements increase the maternal concern and prenatal visits. In this regard, the findings of this study are consistent with the studies have examined the fetal movement charts. One study concluded that the findings of a study has shown that the fetal movement counting had not adverse psychological effects in 613 healthy women [36]. Eggertsen and Benedetti reported that the maternal counting of fetal movement in 394 pregnancies, have been accepted and $85 \%$ of women have reassured [37].

The strength of this study was the experimental plan. 
The participants were predominantly highly educated. Thus, the results can be generalized to similar populations. The Beck Inventory tool is known as a alid and reliable vtool for measuring the depression in pregnancy [20]. The brochure which was given to the mothers about the fetal movements, provided information about the aim of study and improve our knowledge about the counting of fetal movements in pregnant women. Also the aim of study was explained by the midwife to the mothers and the mothers were informed of exposure to fetal movement counting group or control group. This information may increase the general awareness about fetal movements. In the control group, none of women did counting the fetal movements. The overall objective of fetal movement counting, is to reduce the perinatal mortality. It is necessary that a multicentered, randomized, controlled study ivestigate the effect of fetal movement counting on the prenatal mortality rates. Using this easy and inexpensive screening method can be used on low-income women.

\subsection{Conclusions}

Women, who performed fetal movement counting from 28 to 37 weeks of gestation, did not report the lesser depression than those in the control group at 37 weeks of gestation. There was not a significant difference in the number of maternal concern for reducing of fetal movements between the two groups. Further studies are needed to examine and develop the methods to improve the selfscreening of mother for decreased fetal activity in general, and in other areas.

\section{Acknowledgments}

This manuscript was obtained from a research project approved by the research council of Shahrekord University of Medical Sciences and health services (contract no.1226 dated 19 Nov 2013, Masoumeh Delaram). We would like to take this opportunity to express our gratitude to the research deputy of Shahrekord University of medical sciences for supporting this project and the pregnant women for cooperating in this study.

\section{Footnotes}

Authors' Contribution: Masoumeh Delaram designed the study and wrote the manuscript. Loabat Jafar-Zadeh gathered the data and revised the manuscript. Sahand Shams analyzed the data and revised the manuscript.

Conflict of Interest: Authors declared that there is no conflict of interest.

Funding/Support: Deputy of Shahrekord University of Medical Sciences, Shahrekord, Iran.

\section{References}

1. Deshpande SS, Kalmegh B, Patil PN, Ghate MR, Sarmukaddam S, Paralikar VP. Stresses and Disability in Depression across Gender. Depress Res Treat. 2014;2014:735307. doi: 10.1155/2014/735307. [PubMed: 24579042].

2. Highet N, Stevenson AL, Purtell C, Coo S. Qualitative insights into women's personal experiences of perinatal depression and anxiety. Women Birth. 2014;27(3):179-84. doi: 10.1016/j.wombi.2014.05.003. [PubMed: 24951157].

3. Alder J, Fink N, Urech C, Hosli I, Bitzer J. Identification of antenatal depression in obstetric care. Arch Gynecol Obstet. 2011;284(6):1403-9. doi: 10.1007/s00404-011-1872-3. [PubMed: 21424404].

4. Grote NK, Bridge JA, Gavin AR, Melville JL, Iyengar S, Katon WJ. A meta-analysis of depression during pregnancy and the risk of preterm birth, low birth weight, and intrauterine growth restriction. Arch Gen Psychiatry. 2010;67(10):1012-24. doi: 10.1001/archgenpsychiatry.2010.111. [PubMed: 20921117].

5. Field T. Postpartum depression effects on early interactions, parenting, and safety practices: a review. Infant Behav Dev. 2010;33(1):1-6. doi: 10.1016/j.infbeh.2009.10.005. [PubMed: 19962196].

6. Wilson S, Durbin CE. Parental personality disorder symptoms are associated with dysfunctional parent-child interactions during early childhood: a multilevel modeling analysis. Personal Disord. 2012;3(1):55-65. doi: 10.1037/a0024245. [PubMed: 22448861].

7. Hayes LJ, Goodman SH, Carlson E. Maternal antenatal depression and infant disorganized attachment at 12 months. Attach Hum Dev. 2013;15(2):133-53. doi: 10.1080/14616734.2013.743256. [PubMed: 23216358].

8. Villegas L, McKay K, Dennis CL, Ross LE. Postpartum depression among rural women from developed and developing countries: a systematic review. J Rural Health. 2011;27(3):278-88. doi: 10.1111/j.17480361.2010.00339.x. [PubMed: 21729155].

9. Olagbuji BN, Igbarumah S, Akintayo AA, Olofinbiyi BA, Aduloju PO, Alao OO. Maternal understanding of fetal movement in third trimester: a means for fetal monitoring and reducing stillbirth. Niger J Clin Pract. 2014;17(4):489-94. doi:10.4103/1119-3077.134049. [PubMed: 24909475].

10. Delaram M, Shams S. The effect of foetal movement counting on maternal anxiety: A randomised, controlled trial. J Obstet Gynaecol. 2016;36(1):39-43. doi: 10.3109/01443615.2015.1025726. [PubMed: 26204351].

11. Skornick-Rapaport A, Maslovitz S, Kupferminc M, Lessing JB, Many A. Proposed management for reduced fetal movements: five years' experience in one medical center. J Matern Fetal Neonatal Med. 2011;24(4):610-3. doi: 10.3109/14767058.2010.511338. [PubMed: 20828236].

12. Phattanachindakun B, Boonyagulsrirung $T$, Chanprapaph P. The correlation in antepartum fetal test between full fetal biophysical profile (FBP) and rapid biophysical profile (rBPP). J Med Assoc Thai. 2010;93(7):759-64. [PubMed: 20649052]

13. Saastad E, Winje BA, Israel P, Froen JF. Fetal movement countingmaternal concern and experiences: a multicenter, randomized, controlled trial. Birth. 2012;39(1):10-20. doi: 10.1111/j.1523536X.2011.00508.x. [PubMed: 22369601]

14. Saastad E, Israel P, Ahlborg T, Gunnes N, Froen JF. Fetal movement counting-effects on maternal-fetal attachment: a multicenter randomized controlled trial. Birth. 2011;38(4):282-93. doi: 10.1111/j.1523536X.2011.00489.x. [PubMed: 22112328].

15. Mikhail MS, Freda MC, Merkatz RB, Polizzotto R, Mazloom E, Merkatz IR. The effect of fetal movement counting on maternal attachment to fetus. Am J Obstet Gynecol. 1991;165(4 Pt 1):988-91. [PubMed: 1951568]. 
16. Chang HY, Keyes KM, Lee KS, Choi IA, Kim SJ, Kim KW, et al. Prenatal maternal depression is associated with low birth weight through shorter gestational age in term infants in Korea. Early Hum Dev. 2014;90(1):1520. doi: 10.1016/j.earlhumdev.2013.11.006. [PubMed: 24331828].

17. Draper J, Field S, Thomas H, Hare MJ. Womens' views on keeping fetal movement charts. BrJ Obstet Gynaecol. 1986;93(4):334-8. [PubMed: 3964609].

18. Burns A, O'Mahen H, Baxter H, Bennert K, Wiles N, Ramchandani P, et al. A pilot randomised controlled trial of cognitive behavioural therapy for antenatal depression. BMC Psychiatry. 2013;13:33. doi: 10.1186/1471-244X-13-33. [PubMed: 23339584].

19. Alhassan A, Ziblim AR, Muntaka S. A survey on depression among infertile women in Ghana. BMC Womens Health. 2014;14(1):42. doi: 10.1186/1472-6874-14-42. [PubMed: 24612693].

20. Ji S, Long Q, Newport DJ, Na H, Knight B, Zach EB, et al. Validity of depression rating scales during pregnancy and the postpartum period: impact of trimester and parity. J Psychiatr Res. 2011;45(2):213-9. doi: 10.1016/j.jpsychires.2010.05.017. [PubMed: 20542520].

21. Wikberg C, Nejati S, Larsson ME, Petersson EL, Westman J, Ariai N, et al. Comparison Between the Montgomery-Asberg Depression Rating Scale-Self and the Beck Depression Inventory II in Primary Care. Prim Care Companion CNS Disord. 2015;17(3) doi: 10.4088/PCC.14m01758. [PubMed: 26644958].

22. Haga SM, Drozd F, Brendryen H, Slinning K. Mamma mia: a feasibility study of a web-based intervention to reduce the risk of postpartum depression and enhance subjective well-being. JMIR Res Protoc. 2013;2(2):e29. doi: 10.2196/resprot.2659. [PubMed: 23939459].

23. Misri S, Swift E. Generalized Anxiety Disorder and Major Depressive Disorder in Pregnant and Postpartum Women: Maternal Quality of Life and Treatment Outcomes. J Obstet Gynaecol Can. 2015;37(9):798803. doi: 10.1016/S1701-2163(15)30150-X. [PubMed: 26605449].

24. Field T, Deeds O, Diego M, Hernandez-Reif M, Gauler A, Sullivan S, et al. Benefits of combining massage therapy with group interpersonal psychotherapy in prenatally depressed women. J Bodyw Mov Ther. 2009;13(4):297-303. doi: 10.1016/j.jbmt.2008.10.002. [PubMed: 19761951].

25. Meijer JL, Bockting CL, Beijers C, Verbeek T, Stant AD, Ormel J, et al. PRegnancy Outcomes after a Maternity Intervention for Stressful EmotionS (PROMISES): study protocol for a randomised controlled trial. Trials. 2011;12:157. doi: 10.1186/1745-6215-12-157. [PubMed: 21689394].

26. Sit DK, Flint C, Svidergol D, White J, Wimer M, Bish B, et al. Best practices: an emerging best practice model for perinatal depression care. Psychiatr Serv. 2009;60(11):1429-31. doi:10.1176/appi.ps.60.11.1429. [PubMed: 19880455].

27. Ventura T, Gomes MC, Carreira T. Cortisol and anxiety response to a relaxing intervention on pregnant women awaiting amniocentesis. Psychoneuroendocrinology. 2012;37(1):148-56. doi: 10.1016/j.psyneuen.2011.05.016. [PubMed: 21705148].

28. DiPietro JA, Davis MF, Costigan KA, Barr DB. Fetal heart rate and motor activity associations with maternal organochlorine levels: results of an exploratory study. J Expo Sci Environ Epidemiol. 2014;24(5):474-81. doi: 10.1038/jes.2013.19. [PubMed: 23591698].

29. Urech C, Fink NS, Hoesli I, Wilhelm FH, Bitzer J, Alder J. Effects of relaxation on psychobiological wellbeing during pregnancy: a randomized controlled trial. Psychoneuroendocrinology. 2010;35(9):134855. doi: 10.1016/j.psyneuen.2010.03.008. [PubMed: 20417038].

30. Qiao Y, Wang J, Li J, Wang J. Effects of depressive and anxiety symptoms during pregnancy on pregnant, obstetric and neonatal outcomes: a follow-up study. J Obstet Gynaecol. 2012;32(3):237-40. doi 10.3109/01443615.2011.647736. [PubMed: 22369395].

31. Madigan S, Wade M, Plamondon A, Vaillancourt K, Jenkins JM Shouldice $\mathrm{M}$, et al. Course of depression and anxiety symptoms during the transition to parenthood for female adolescents with histories of victimization. Child Abuse Negl. 2014;38(7):1160-70. doi: 10.1016/j.chiabu.2014.04.002. [PubMed: 24862921].

32. Le HN, Perry DF, Stuart EA. Randomized controlled trial of a preventive intervention for perinatal depression in high-risk Latinas. J Consult Clin Psychol. 2011;79(2):135-41. doi: 10.1037/a0022492. [PubMed: 21319897].

33. Glover V. Maternal depression, anxiety and stress during pregnancy and child outcome; what needs to be done. Best Pract Res Clin Obstet Gynaecol. 2014;28(1):25-35. doi: 10.1016/j.bpobgyn.2013.08.017. [PubMed: 24090740].

34. Smith R, Maiti K, Aitken RJ. Unexplained antepartum stillbirth: a consequence of placental aging?. Placenta. 2013;34(4):310-3. doi: 10.1016/j.placenta.2013.01.015. [PubMed: 23452441].

35. Neldam S. Fetal movements as an indicator of fetal wellbeing. Lancet 1980;1(8180):1222-4. [PubMed: 6104039].

36. Liston RM, Bloom K, Zimmer P. The psychological effects of counting fetal movements. Birth. 1994;21(3):135-40. [PubMed: 7857455].

37. Eggertsen SC, Benedetti TJ. Maternal response to daily fetal movement counting in primary care settings. Am J Perinatol. 1987;4(4):32730. doi: 10.1055/s-2007-999801. [PubMed: 3651191]. 